\title{
Use of Student-Generated Multiple Choice Questions to Enhance Team-Based Learning of Anatomy at the University of Rwanda
}

This article was published in the following Dove Press journal:

Advances in Medical Education and Practice

\author{
Isaie Sibomana $\mathbb{D}^{\text {' }}$ \\ Irenee David Karenzi ${ }^{\prime}$ \\ Irenee Niyongombwa $\mathbb{D}^{\prime}$ \\ Jean Claude Byiringiro (1D) \\ Julien Gashegu ${ }^{2}$ \\ Faustin Ntirenganya (D) \\ 'Department of Surgery, College of \\ Medicine and Health Sciences, University \\ of Rwanda, Kigali, Rwanda; ${ }^{2}$ Department \\ of Anatomy, College of Medicine and \\ Health Sciences, University of Rwanda, \\ Butare, Rwanda
}

Introduction: Teaching of human anatomy has undergone significant changes in the past three decades. At the University of Rwanda, anatomy is being taught using team-based learning (TBL). While student-generated multiple choice questions (MCQs) stimulate deeper thinking on a given topic, their impact on anatomy learning is not known. This study aimed to find out the impact of student-generated MCQs on the current anatomy teaching method at the University of Rwanda.

Methods: In this comparative interventional study, two similar chapters on anatomy were selected; one was taught using TBL while for the other one, in addition to TBL, students were encouraged to set MCQs while studying. Pre- and post-test scores were analyzed using SPSS 23 and the Student's $t$-test was used to compare the mean scores obtained.

Results: Thirty-one medical students were recruited. Pre-test mean scores were 25.10 and 25.19 out of 50 for chapters 1 and 2, respectively. Although the students' post-test scores improved after teaching for each chapter, the improvement was much greater for chapter 2 than for chapter 1 , with mean scores of 39.97 and 32.45 out of 50 , respectively $(P<0.05)$. Despite such improvement, almost half of the students found that setting MCQs was not easy.

Conclusion: This study found that student-generated MCQs can be used as a simple and cost-effective tool to enhance TBL of anatomy.

Keywords: anatomy, teaching, MCQs, TBL, University of Rwanda

\section{Introduction}

Human anatomy is the science of human structures and their relationships with one another. It is subdivided into gross anatomy, which deals with the structures and position of organs; histology, which is occupied with the microscopic appearance of cells and tissues; and embryology, which studies fetal development. ${ }^{1}$ Human anatomy is one of the cornerstones of medical curricula and is fundamental for safe clinical practice, especially in surgery. ${ }^{2-4}$

With time constraints and increasing numbers of medical students per class, in addition to the limited number of cadavers for dissection, anatomy teaching has undergone significant changes in the past three decades. ${ }^{1,5,6}$ Traditional teaching methodologies of anatomy basically comprised cadaver dissections, inspection of prosections or plastinations, and didactic teachings. ${ }^{1}$ With the increasing use of technology in academia, methods have shifted to the use of models in teaching, computer-based learning and teaching based on radiological images. ${ }^{1,2}$
Correspondence: Isaie Sibomana Department of Surgery, College of Medicine and Health Sciences, University of Rwanda, 655 Kigali, Kigali, Rwanda Tel +250788558658

Email siibomana@gmail.com
Advances in Medical Education and Practice 2020: I I 825-832 
While instructors of human anatomy have been overloaded by the large volume of anatomy study materials and time constraints, other teaching methodologies, such as team-based learning (TBL), have been tried, where students are encouraged to be active and take responsibility for learning. ${ }^{7}$ These teaching styles give an opportunity for students to interact with others and to apply conceptual knowledge through working in small groups. ${ }^{7,8}$ TBL also overcomes the problem of a shortage of anatomy lecturers in some universities. ${ }^{9}$

All of these teaching changes are intended to increase the knowledge of anatomy. However, no single method has been found to be best, and a multimodal approach is favored., ${ }^{2,5}$

Several other methodologies have been tried in medicine to cope with curricula and student satisfaction, one of which is student-generated multiple choice questions (MCQs). It is thought that if students are encouraged to make up their own MCQs while studying, this stimulates deeper understanding of the topic; and it has been found that the knowledge required to set a good MCQ is usually greater than that required to answer one. ${ }^{10}$

At the University of Rwanda, didactic methods were initially used to teach anatomy, but with an increasing number of medical students, this has shifted toward PowerPoint presentations, and since 2013, TBL has been introduced at the university as the teaching methodology, only for anatomy. No prior studies have been conducted at the university to address the impact of such changes, although they are satisfactory for both lecturers and students. As there is still much room for improvement using other interventions aimed at improving anatomy science delivery at the university, student-generated MCQs could be one of the simplest interventions, if applied correctly.

\section{Methods}

This study aimed to improve anatomy learning and knowledge retention at the University of Rwanda by determining the impact of student-generated MCQs on team-based anatomy learning.

A comparative interventional study was conducted by comparing TBL and TBL enhanced by student-generated MCQs (TBL+) as teaching methodologies for the anatomy course at the University of Rwanda.

The study recruited 31 final year medical students who were rotating in the surgical department at the University Teaching Hospital of Kigali (CHUK) from January 2019 to February 2019. During their clinical rotation, two chapters on surgically oriented anatomy were chosen among other teaching aids and were included in this study. These chapters were selected based on their having similar length and level of complexity in the standard anatomy textbooks. Both chapters were taught by the same lecturer but not at the same time; chapter 1 was taught first, and after its completion, chapter 2 followed.

During the first chapter (innervation of the upper limb), students used the current teaching methodology for anatomy learning at the University of Rwanda, which is teambased learning.

\section{Description of Chapter I Teaching}

- Teaching on the chapter lasted for 1 week.

- On the first day, the lecturer gave an introduction to the chapter and study materials to the students (textbooks, CDs).

- A pre-test was given to the students to measure their baseline knowledge of the chapter.

- Each group was formed by five or six students, chosen randomly.

- Students were instructed to spend a minimum of 2 hours/day discussing the topic in their respective groups.

- After 5 days, the lecturer conducted individual and team readiness assurance tests using MCQs, and guided the students in clinical problem solving.

- The post-test assessment test was carried out on day 7 using a different set of MCQs.

The second chapter (innervations of the lower limb) was taught using the new teaching methodology (TBL+), where students were instructed to set their own MCQs while studying.

\section{Description of Chapter 2 Teaching}

- Teaching on chapter 2 also lasted for 1 week. The same environment as for Chapter 1 was provided for learning.

- The lecturer started by providing an introduction to the chapter and giving study materials to the students (textbooks, CDs).

- Students were also taught about how to set highquality MCQs and introduced to Bloom's taxonomy of categorizing questions into different levels of complexity and specificity.

- A pre-test was performed to measure the baseline knowledge of students on the chapter with the use of MCQs. 
- Students remained in their respective groups of five or six students.

- A minimum of 2 hours/day was the requirement for each group to discuss the topic.

- During this chapter, they were encouraged to set at least five MCQs/group and to discuss them while studying.

- After 4days, the lecturer collected student-generated MCQs to assess their quality and to find out whether they met the study objectives. All well-set MCQs were given back to students on day 5 to discuss them in depth before the post-test assessment, which was carried out on day 7 . On the same day (day 5), students were also assessed on individual and team readiness using MCQs set by the lecturer and guided in clinical problem solving.

\section{Post-Study Survey}

To understand students' perceptions on the new teaching methodology, a survey questionnaire was developed and given to the students after the study. This questionnaire, based on a five-point Likert scale, was initially tested in four pilot students (about 12\% of respondents) to address whether there was confusion regarding the items and whether the respondents understood the questions in the same way as the questionnaire developer.

\section{Data Collection and Analysis}

The study included the following variables: student demographics, pre- and post-test scores for the innervations of the upper limb, and pre- and post-test scores for the innervations of the lower limb. SPSS software version 23 was used for data analysis. The mean and standard deviation were basic statistics calculated for individual students' scores and were also used to report demographic data. The Student's paired $t$-test was employed to determine and compare the mean scores obtained after the two chapter assessments. Post-study evaluation consisted of a SurveyMonkey online questionnaire of prepared and tested questions based on a Likert scale ranging from 1 to 5 points.

\section{Results}

The study recruited 31 medical students. Their age ranged from 23 to 30 years, with a mean $\pm \mathrm{SD}$ age of $25 \pm 1.599$ years. There were 22 males (71\%) and nine females (29\%). Although they were all final year medical students, some were on level 5 (15 students) while 16 were on level 6 of training.

The pre-test minimum score for the upper limb was $17 / 50$ and the maximum was $30 / 50$, with a mean \pm SD score of 25.10 \pm 3.18 . The minimal pre-test score for the lower limb was 16 / 50 and the maximum was $32 / 50$, with a mean score of 25.19 \pm 3.73 , and there was no statistically significant difference between the mean scores obtained $(P=0.885)$ (Figure 1 ).

The independent sample $t$-test was used to determine differences in mean score between level 5 and level 6 students' pre-test scores for both chapters. Although the students were at different levels of training, their baseline scores were not statistically significantly different (Table 1).

Post-test scores for both chapters were compared with pre-test scores using the Student's $t$-test. Overall, there was an increase in students' scores after the tests for both chapters (Table 2). However, students scored better on the post-test for chapter 2 than for chapter 1 , with a mean difference of $7.515(P<0.05)$ (Figure 2).

During the second chapter, the students set 35 MCQs. The questions were corrected and analyzed by the lecturer to appraise their quality, by assessing mainly:

- Whether the set MCQs covered the study objectives

- Whether they were written in clear and understandable language

- The way in which the proposed answer and distractors were constructed.

\section{Quality of MCQs Generated by Students During Chapter 2}

Of $35 \mathrm{MCQs}$, six (18\%) were found to be poor-quality questions based on the above criteria and the remaining 29 were further assessed for their complexity based on different domains of Bloom's taxonomy. Among good MCQs, $62.5 \%$ demonstrated adequate medical knowledge by recalling the anatomical concepts, while only the remaining $37.5 \%$ of questions demonstrated a higher level of thinking (Table 3 ).

\section{Post-Study Survey Results}

All 31 students answered the post-study survey, which was prepared based on a five-point Likert scale. The developed questionnaire comprised eight questions which were tested in a pilot study with four students randomly selected from the study participants. These pilot students could clearly 


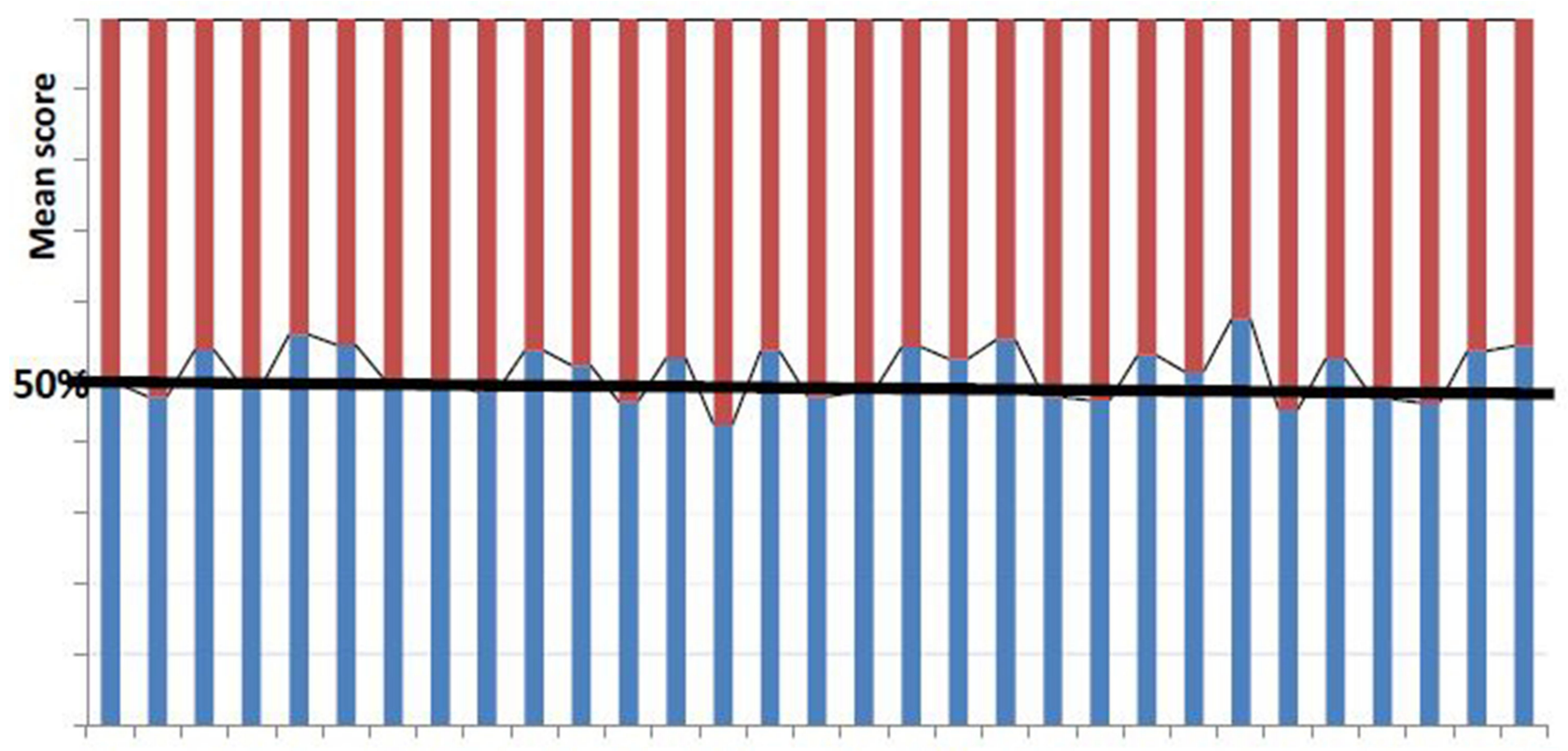

$122 \quad 3 \quad 4 \quad 5 \quad 6 \quad 7 \quad 8 \quad 910111213141516171819202122232425262728293031$

\section{Number of students}

\section{pretest upper limb $\quad$ pre test lower limb}

Figure I Students' pre-test scores for upper and lower limb nerve supply.

grasp the meaning of five out of eight questions on the survey. The other two questions were either difficult or meaningless for them to answer and therefore were removed from the survey questions. The remaining question on the survey asked about the level of difficulty in setting MCQs; of 31 students, 14 (45\%) found that it was

Table I Pre-Test Scores Variation Depending on the Level of Training of Students

\begin{tabular}{|l|l|l|l|l|l|l|l|}
\hline Pre-Test Scores & Level of Training & Number (\%) & Mean Score/50 & SD & \multicolumn{2}{l|}{$P$ value } & \multicolumn{2}{l|}{ Mean Difference } & \multicolumn{2}{l}{ 95\% Cl of the Difference } \\
\cline { 3 - 7 } & & & Upper & \\
\hline Chapter I & $\begin{array}{l}\text { Level 5 } \\
\text { Level 6 }\end{array}$ & $\begin{array}{l}15(48.38) \\
16(51.62)\end{array}$ & $\begin{array}{l}24.4 \\
25.75\end{array}$ & $\begin{array}{l}2.613 \\
3.606\end{array}$ & 0.245 & -1.350 \\
\hline Chapter 2 & Level 5 & $\begin{array}{l}15(48.38) \\
16(51.62)\end{array}$ & $\begin{array}{l}25.13 \\
25.25\end{array}$ & $\begin{array}{l}3.441 \\
4.107\end{array}$ & 0.933 & -0.117 \\
\hline
\end{tabular}

Table 2 Paired $t$-Test for Chapter I and Chapter 2 Comparing the Mean Pre-Test and Post-Test Scores

\begin{tabular}{|c|c|c|c|c|c|c|c|c|c|c|}
\hline \multirow[t]{3}{*}{ Chapter Scores } & \multirow[t]{3}{*}{ Mean } & \multirow[t]{3}{*}{$\mathbf{N}$} & \multirow[t]{3}{*}{ SD } & \multicolumn{5}{|c|}{ Paired Differences } & \multirow[t]{3}{*}{$t$} & \multirow[t]{3}{*}{$P$ value } \\
\hline & & & & \multirow[t]{2}{*}{ Mean Diff. } & \multirow[t]{2}{*}{ SD } & \multirow[t]{2}{*}{ SEM } & \multicolumn{2}{|c|}{$95 \% \mathrm{Cl}$ of the Difference } & & \\
\hline & & & & & & & Lower & Upper & & \\
\hline Pre-test (Chapter I) & 25.1 & 31 & 3.187 & -7.355 & 4.378 & 0.786 & -8.961 & -5.749 & -9.353 & 0 \\
\hline Post-test (Chapter I) & 32.45 & 31 & 4.675 & & & & & & & \\
\hline Pre-test (Chapter 2) & 25.19 & 31 & 3.736 & -14.77 & 5.714 & 1.026 & -16.87 & -12.67 & -14.39 & 0 \\
\hline Post-test (Chapter 2) & 39.97 & 31 & 5.05 & & & & & & & \\
\hline
\end{tabular}




\section{Post-test scores comparing chapter 1 and chapter 2}

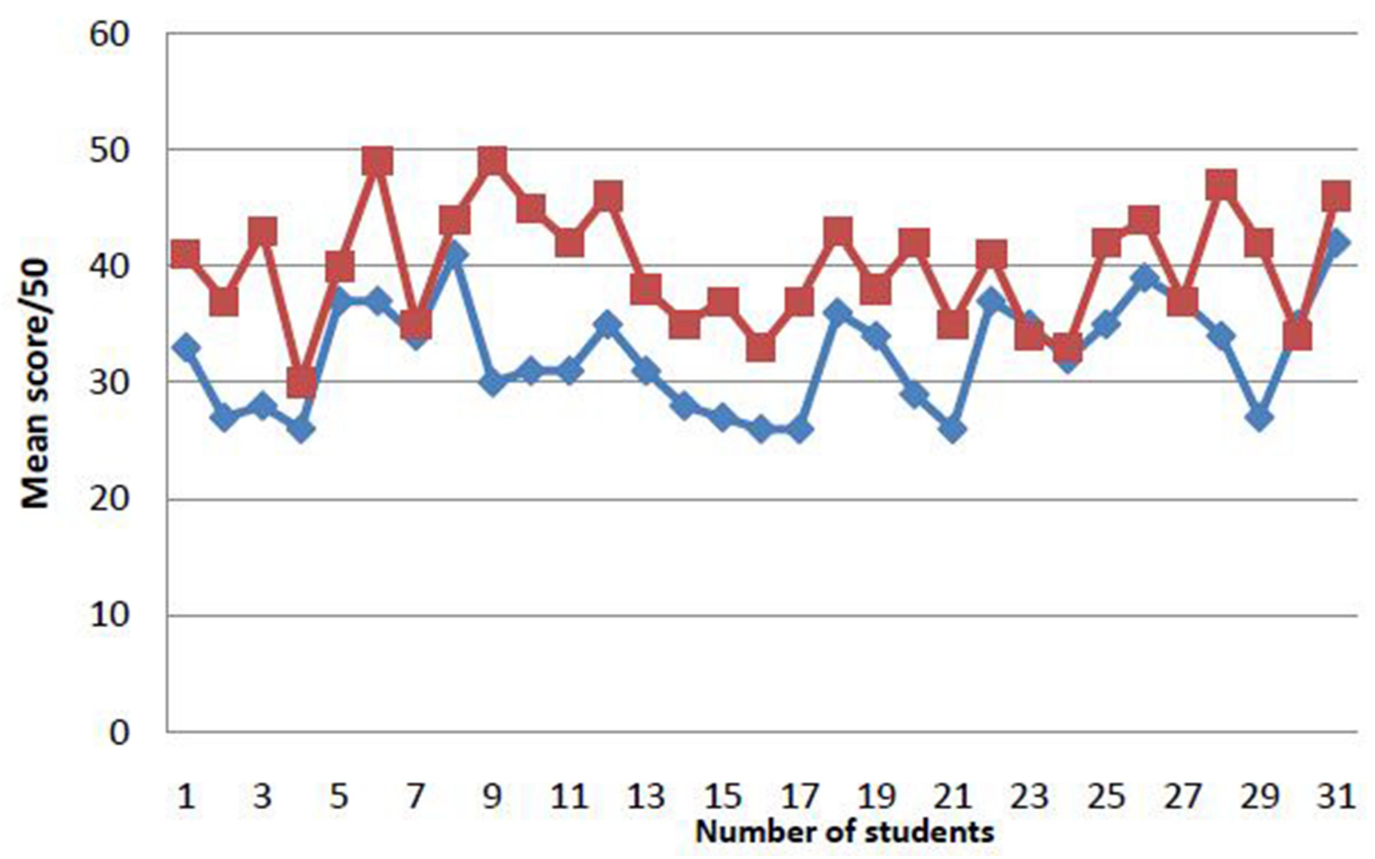

Figure 2 Post-test scores for chapter I and chapter 2.

not easy to set MCQs, while it was neither easy nor difficult for 5 students (16\%). However, only 12 students (39\%) found that it was very easy to set MCQs

The rest of the survey questions and results are presented in Figure 3; almost $70 \%$ of students found selfgenerated MCQs very helpful in their learning during the second chapter.

\section{Discussion}

This interventional study was the first one conducted at the University of Rwanda to test the impact of student-

Table 3 Categorization of Student-Generated MCQs in Different Domains of Bloom's Taxonomy

\begin{tabular}{|l|l|}
\hline $\begin{array}{l}\text { Bloom's Categorization of MCQs Generated } \\
\text { by Students }\end{array}$ & $\begin{array}{l}\text { \% of } \\
\text { Questions }\end{array}$ \\
\hline $\begin{array}{l}\text { Knowledge (questions that are only based on } \\
\text { recognition or recall of memorized information) }\end{array}$ & 62.5 \\
\hline $\begin{array}{l}\text { Comprehension/Application/Analysis/Synthesis/ } \\
\text { Evaluation (questions that demonstrate a higher level } \\
\text { thinking and which make important goals for } \\
\text { education) }\end{array}$ & 37.5 \\
\hline
\end{tabular}

generated MCQs on the current anatomy teaching methodology (team-based learning).

This study recruited medical students in their final year of training. They had prior exposure to the anatomy course in their first year of medical school. Ideally, the best potential candidates for the study would have been first year medical students without prior knowledge of anatomy. However, we selected two anatomy topics which are more surgically oriented than gross anatomy and which the students had not learnt in depth during the first year of medical school. Unlike other studies on the impact of MCQs on learning, this is the only study to have evaluated the impact of student-generated MCQs on TBL of an anatomy course.

Previous studies on the impact of MCQs on student learning did not mention the prior knowledge of students on the study materials to which they were exposed. ${ }^{11,12}$ The fact that the medical students recruited into this study were not at the same level of training (level 6 and level 5) did not result in selection bias as they all had similar baseline anatomy knowledge, with mean score differences of $1.35(P=0.245)$ and $0.117(P=0.933)$ for the first and the second chapters, respectively. 


\section{Post study survey}

\section{Questions asked}

I recommend self-structured MCQs to be used in subsequent chapters of anatomy

I feel more responsible when I am using self structured MCQs for learning

self structured MCQs increased my interactive with other students

self structured MCQs helped me to understand deeply the second chapter

Self-structured MCQs improved my learning of the anatomy course

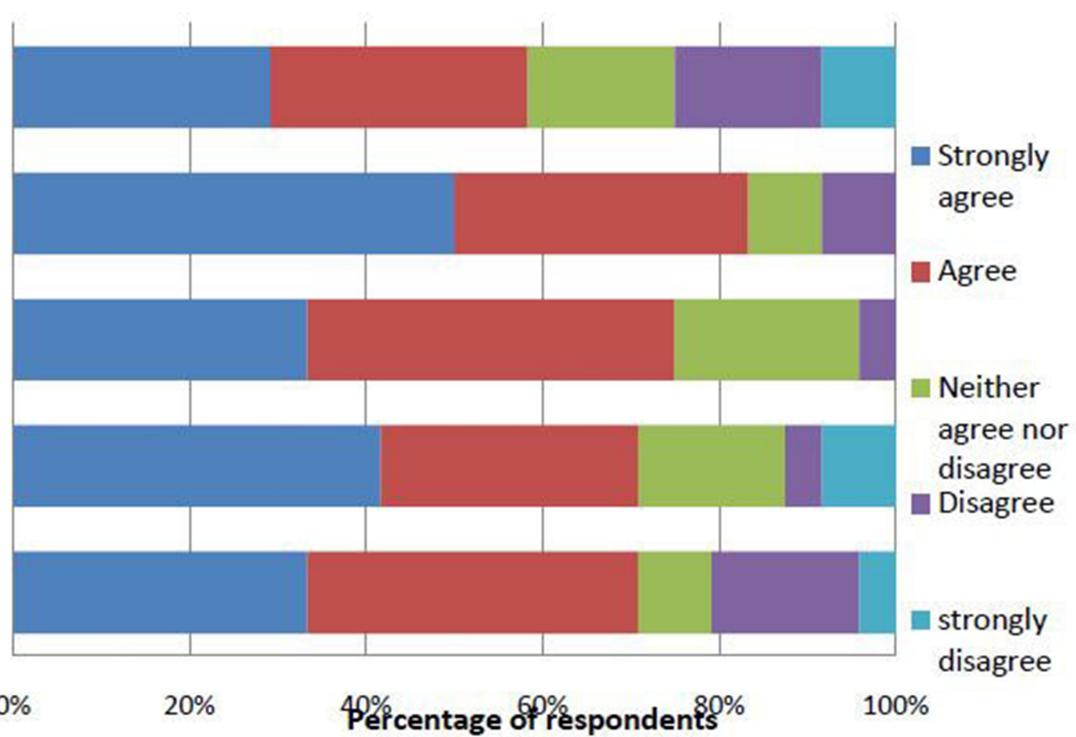

Figure 3 Students' perceptions on the new teaching methodology.

Students' scores on two different topics are usually expected to differ based on various factors such as differences in complexity between the topics, length, environment and available time for studying. These confounders were controlled by selecting two similar topics in the standard anatomy textbooks, and pre-tests for both chapters were undertaken before the start of teaching, which showed almost the same level of baseline knowledge (Figure 1), with student pre-test mean scores of 25.10/50 and 25.19/50 for chapters 1 and 2, respectively. However, the fact that the learning should have improved over time after the first chapter was difficult to control, and the decision to start the experiment with the chapter on upper limb innervation rather than starting on the lower limb was not based on any other criteria, but was also found to be a confounder.

In addition to TBL, students were requested to set MCQs while studying chapter 2 . Their mean scores improved from 25.19 to 39.93 for pre-test and post-test, respectively $(P<0.05)$. Compared with chapter 1 , there was a great improvement in student mean score at the end of the chapter assessments, from 32.45 to 39.93 for control and intervention arms, respectively. Analysis with the independent $t$-test showed that the difference in scores was statistically significant $(P<0.05)$. These results are comparable to those found by Shakurnia et al in their study which tested the effect of MCQ generation on midwifery students' learning on an immunology course, where there was a significant increase in post-test score in the group that used MCQs as a learning tool compared with the control group. ${ }^{12}$ Unlike that study, where the students did not have prior knowledge of immunology, our students had prior knowledge of anatomy from their first year of medical school, which can make interpretation of the results difficult.

The improvement in student scores after chapter 2 should be viewed from different angles. The fact that chapter 2 was taught after completion of chapter 1 should have led to improved learning skills of the students over time and therefore improved post-test scores. A crossover design would have been suitable for this study or, if possible, students should have been randomized into two categories where one group could use either method. The improved student score should have also resulted in chapters which were different; although the students demonstrated the same baseline medical knowledge based on the pre-test score, the chapters were not identical and students would probably have had fewer difficulties in studying chapter 2 than chapter 1.

During the second chapter, students were asked to set MCQs while studying. The quality of MCQs set was analyzed using Bloom's taxonomy and classified according to its cognitive domains for questions which test knowledge, comprehension, application, analysis, synthesis and evaluation. ${ }^{13}$

Of the good questions set by the students, $62.5 \%$ were testing knowledge, as students were only recalling the 
memorized anatomical concepts. However, only $37.5 \%$ were categorized into the higher cognitive domain. These findings are similar to those found by Palmer et al, who evaluated the impact and quality of student-constructed MCQs on learning clinical surgery at the University of Adelaide, where students were able to produce only $25 \%$ of MCQs testing higher cognitive skills, while many questions tested knowledge and comprehension. ${ }^{10}$ The students were unfamiliar with the task of setting MCQs, and did not have sufficient time to develop the skills necessary for setting MCQs.

Several other studies have highlighted the benefits of MCQs for learning in general, which include active learning and development of higher thinking skills in problem solving. ${ }^{10,11}$ As shown in our study, the adjunctive effect of student-generated MCQs on current TBL of the anatomy course was positive based on student performance scores and appreciation after the study, but as this was the first study conducted on anatomy teaching, randomized studies are needed.

Setting MCQs is an exercise that requires adequate knowledge of the subject and higher thinking skills. However, none of the studies that proved the benefits of student-constructed MCQs as a stimulus to learning evaluated the time required to accomplish this task. As anatomy constitutes a large module in the preclinical years of medical school, students may be overloaded by the extra work involved in generating MCQs on top of the preexisting huge amount of anatomy study material, and this needs to be addressed in further studies.

In contrast to our findings, the study by Grainger et al recognized the benefits of student-generated MCQs on improvement of learning, but the students perceived negatively the task of setting questions, mainly because of inadequate question-writing skills and the extra work requiring a high cognitive load for them to generate highquality MCQs. ${ }^{14}$

\section{Study Limitations}

- These chapters in the standard anatomical textbooks were very short; usually, TBL at the University of Rwanda is carried out by assessing students after they have studied a large component of the course, such as anatomy of the head, neck, trunk or upper limb. Therefore, students could easily memorize the chapters used in this study, which could potentially impact the post-test scores.

- The fact that the scores obtained would not have an impact on students' continuous assessment could have led to some students not to making an effort while studying.

- The students' perceptions on the new learning methodology were based on a five-point Likert scale, which did not allow them to express all of their thoughts.

- The small sample size was also a limitation of this study; we recommend that further studies recruit an entire class instead of a small group and use a two-arm randomization process for better understanding of the impact of student-generated MCQs on TBL of anatomy.

\section{Conclusion}

The results of this study show that there was much improvement in student performance using studentgenerated questions as a stimulus to learning, and therefore this is a simple and cost-effective tool to enhance TBL of anatomy at the University of Rwanda. However, students need to be familiarized with the principles of setting good and formative MCQs.

\section{Abbreviations}

$\mathrm{CD}$, compact disc; CMHS/IRB, College of Medicine and Health Sciences/institutional Review Board; MCQ, multiple choice question; SD, standard deviation; TBL, team-based learning; TBL+, team-based learning plus student-generated multiple choice questions.

\section{Data Sharing Statement}

The datasets used and/or analyzed during the current study are available from the corresponding author on reasonable request.

\section{Ethical Approval and Consent to Participate}

This study was approved by the Institutional Review Board of the College of Medicine And Health Sciences of the University of Rwanda (record number: 334/CMHS IRB/2018). Consent for participation was given by each participant prior to the study.

\section{Funding}

This study did not receive any funding.

\section{Disclosure}

The authors report no conflicts of interest for this work. 


\section{References}

1. Brenton H, Hernandez J, Bello F, et al. Using multimedia and Web3D to enhance anatomy teaching. Comput Educ. 2007;49:32-53.

2. Estai M, Bunt S. Best teaching practices in anatomy education: a critical review. Ann Anat. 2016;208:151-157. doi:10.1016/j. aanat.2016.02.010

3. Bay BH, Ling EA. Teaching of anatomy in the new millennium. Singapore Med J. 2007;48(3):182-183.

4. Papa V, Vaccarezza M, Liston R. Teaching anatomy in the XXI century: new aspects and pitfalls. Sci World J. 2013;2013:1-5. doi: $10.1155 / 2013 / 310348$

5. Al-mohrej OA, Al-ayedh NK, Masuadi EM, Al- NS. Learning methods and strategies of anatomy among medical students in two different institutions in Riyadh, Saudi Arabia. Med Teach. 2017;39(sup1):S15S21. doi:10.1080/0142159X.2016.1254737

6. Chapman SJ, Hakeem AR, Marangoni G, Prasad KR. Annals of anatomy anatomy in medical education: perceptions of undergraduate medical students. Ann Anat. 2013;195(5):409-414. doi:10.1016/j. aanat.2013.03.005

7. Mart EG, Tuesca R. Modified team-based learning strategy to improve human anatomy learning: a pilot study at the universidad del norte in Barranquilla, Colombia. Anat Sci Educ. 2014;405:399-405.
8. Kinsella BGK, Mahon C, Lillis S. Facilitating active engagement of the university student in a large-group setting using group work activities. J Coll Sci Teach. 2017;46(6):34-42. doi:10.2505/4/ jcst17_046_06_34

9. Yan J, Ding X, Xiong L, et al. Team-based learning: assessing the impact on anatomy teaching in People's Republic of China. Adv Med Educ Pract. 2018;9:589-594. doi:10.2147/AMEP.S169949

10. Palmer E, Hons BE, Devitt P. Constructing multiple choice questions as a method for learning. Ann Acad Med Singapore. 2006;35:604-608.

11. Hutchinson D, Wells J. An inquiry into the effectiveness of student generated mcqs as a method of assessment to improve teaching and learning. Sci Res. 2013;4(7):117-125.

12. Shakurnia A, Aslami M, Bijanzadeh M. The effect of question generation activity on students' learning and perception. $J$ Adv Med Educ Prof. 2018;6(2):70.

13. Kadiyala S, Gavini S, Kumar DS, Kiranmayi V, Srinvasa R. Applying blooms taxonomy in framing MCQs: an innovative method for formative assessment in medical students. J NTR Univ Heal Sci. 2017;6 (2):86-91. doi: $10.4103 / 2277-8632.208010$

14. Grainger R, Dai W, Osborne E, Kenwright D. Medical students create multiple-choice questions for learning in pathology education: a pilot study. BMC Med Educ. 2018;18(1):1-8. doi:10.1186/s12909-018$1312-1$
Advances in Medical Education and Practice

\section{Publish your work in this journal}

Advances in Medical Education and Practice is an international, peerreviewed, open access journal that aims to present and publish research on Medical Education covering medical, dental, nursing and allied health care professional education. The journal covers undergraduate education, postgraduate training and continuing medical education

\section{Dovepress}

including emerging trends and innovative models linking education, research, and health care services. The manuscript management system is completely online and includes a very quick and fair peer-review system. Visit http://www.dovepress.com/testimonials.php to read real quotes from published authors. 